\title{
Outcomes of elective induction of labour compared with expectant management: population based study
}

\author{
(C) $(1) \Theta$ OPEN ACCESS
}

\author{
Sarah J Stock clinical lecturer and subspecialty trainee in maternal fetal medicine ${ }^{1}$, Evelyn Ferguson \\ consultant obstetrician ${ }^{2}$, Andrew Duffy information analyst ${ }^{3}$, lan Ford professor of biostatistics ${ }^{4}$, \\ James Chalmers consultant in public health medicine ${ }^{3}$, Jane $\mathrm{E}$ Norman professor of maternal and \\ fetal health ${ }^{1}$
}

${ }^{1}$ Tommy's Centre for Maternal and Fetal Health, MRC Centre for Reproductive Health, University of Edinburgh, Queen's Medical Research Institute, Edinburgh EH16 4SA, UK; ${ }^{2} \mathrm{NHS}$ Lanarkshire, Wishaw General Hospital, Wishaw, UK; ${ }^{3}$ Information Services Division, NHS National Services Scotland, Edinburgh; ${ }^{4}$ University of Glasgow Robertson Centre for Biostatistics, Glasgow, UK

\begin{abstract}
Objective To determine neonatal outcomes (perinatal mortality and special care unit admission) and maternal outcomes (mode of delivery, delivery complications) of elective induction of labour compared with expectant management.

Design Retrospective cohort study using an unselected population database.

Setting Consultant and midwife led obstetric units in Scotland 1981-2007.

Participants 1271549 women with singleton pregnancies of 37 weeks or more gestation.

Interventions Outcomes of elective induction of labour (induction of labour with no recognised medical indication) at 37, 38, 39, 40, and 41 weeks' gestation compared with those of expectant management (continuation of pregnancy to either spontaneous labour, induction of labour or caesarean section at a later gestation).
\end{abstract}

Main outcome measures Extended perinatal mortality, mode of delivery, postpartum haemorrhage, obstetric anal sphincter injury, and admission to a neonatal or special care baby unit. Outcomes were adjusted for age at delivery, parity, year of birth, birth weight, deprivation category, and, where appropriate, mode of delivery.

Results At each gestation between 37 and 41 completed weeks, elective induction of labour was associated with a decreased odds of perinatal mortality compared with expectant management (at 40 weeks' gestation $0.08 \%(37 / 44764)$ in the induction of labour group versus $0.18 \%$ $(627 / 350643)$ in the expectant management group; adjusted odds ratio $0.39,99 \%$ confidence interval 0.24 to 0.63 ), without a reduction in the odds of spontaneous vertex delivery (at 40 weeks' gestation $79.9 \%$ (35 $775 / 44778)$ in the induction of labour group versus $73.7 \%$ (258 665/350 791 ) in the expectant management group; adjusted odds ratio 1.26, 1.22 to 1.31). Admission to a neonatal unit was, however, increased in association with elective induction of labour at all gestations before 41 weeks (at 40 weeks' gestation 8.0\% (3605/44 778) in the induction of labour group compared with $7.3 \%$ (25 572/350 791) in the expectant management group; adjusted odds ratio $1.14,1.09$ to 1.20 ).

Conclusion Although residual confounding may remain, our findings indicate that elective induction of labour at term gestation can reduce perinatal mortality in developed countries without increasing the risk of operative delivery.

\section{Introduction}

Induction of labour is carried out in over $20 \%$ of pregnancies in developed countries. ${ }^{1}$ It is indicated when interrupting the pregnancy is thought to be advantageous for the mother or baby and is often carried out for postdate pregnancies ( $>41$ weeks' gestation), where it has been shown to decrease perinatal mortality. ${ }^{2}$ As perinatal mortality and fetal compromise increase progressively with gestation beyond 37 weeks, ${ }^{3}$ induction of labour between 37 and 41 weeks has the potential to improve neonatal outcomes. However, no trial or meta-analysis with adequate sample size has been done to examine the effect of induction of labour between 37 and 41 weeks' gestation on perinatal mortality. ${ }^{2}$ Some studies have suggested that elective induction of labour (the induction of labour in the absence of medical indications) after 37 weeks' gestation is associated with increased obstetric intervention, particularly caesarean delivery. ${ }^{4-7}$ Conversely, when induction of labour is carried out after 37 weeks' gestation in the presence of medical indications such as gestational hypertension, it reduces the risk of adverse maternal outcomes. ${ }^{8}$ None of these previous studies has been 
powered to detect the effects of induction of labour on perinatal mortality.

Robust evidence on the risks and benefits of induction of labour is needed to guide decisions about pregnancy management. Where outcomes are uncommon (for example, perinatal death) clinical trials are rarely feasible owing to the large sample size required. In this scenario epidemiological analysis of patient populations can be useful in identifying associations between an intervention and an outcome. ${ }^{9-11}$ Using a validated unselected population database of over 1.6 million pregnancies linked to a database on neonatal outcomes, we determined perinatal mortality and maternal complications after elective induction of labour at term, and compared them with those of expectant management.

\section{Methods}

We carried out a population based retrospective cohort study of singleton pregnancies delivered at 37 weeks' gestation or greater between 1 January 1981 and 31 December 2007.

\section{Databases}

We obtained data from the Scottish Morbidity Record 02 and 11, Scottish birth record, Scottish stillbirth and infant death survey, and General Register Office for Scotland database, which contains linked maternity, neonatal, and stillbirth/infant death records. The Scottish Morbidity Record 02 contains information on all women discharged from Scottish maternity units. The level of completeness over the period studied is estimated to be in excess of $98 \% .{ }^{12}$ Scottish Morbidity Record 11, now replaced by the Scottish birth record, contains information on neonatal outcomes. The Scottish stillbirth and infant death survey is based on stillbirths and infant deaths that are registered with the General Register Office for Scotland, with registration mandated by law after a perinatal death.

At the start of our study, data in the linked maternity database were complete and validated between and including 1981 and 2007. To maximise the study's power to examine the effect of induction of labour on perinatal mortality we examined deliveries between January 1981 and December 2007. We used standard codes and definitions (international classification of diseases, ninth and 10th revisions); see the supplementary table for details of the codes and database fields.

\section{Indication for induction of labour}

We categorised the women as having elective inductions if they had no medical indication for induction of labour. The indication for induction of labour is not recorded on Scottish Morbidity Record 02, unlike medical complications of pregnancy. The presence of the following conditions was assumed to confer a medical indication for induction: hypertensive or renal disorders, thromboembolic disease, diabetes mellitus, liver disorders, pre-existing medical disorder, antenatal investigation of abnormality, suspected fetal abnormality or fetal compromise, and poor obstetric history (previous stillbirth or neonatal death). In the absence of any of these conditions being recorded, we considered the induction of labour before 41 weeks to be elective.

\section{Comparison groups}

In our primary analysis, for each gestation in the induction of labour cohort we identified a comparison group representing women who were expectantly managed and who delivered after the gestation at which the comparator induction of labour was performed. Thus we compared the outcomes of women who underwent induction of labour and delivered at 36 completed weeks' gestation with those of women who delivered at 38 weeks and beyond; we compared women who underwent induction of labour and delivered at 38 weeks' gestation with women who delivered at 39 weeks and beyond; and so on.

Using further analyses we explored the effect of potential biases on results. Because gestation is recorded only in completed weeks, and not in weeks and days, we recognise that some women who were expectantly managed could have delivered promptly within the same week, and that to exclude these women might artificially inflate the benefit of induction of labour on caesarean section. ${ }^{13}$ We therefore carried out a secondary analysis with the comparator being women delivering at or beyond the gestation of induction of labour. Some of this comparison group may indeed have delivered at a slightly earlier gestation than the induction group

\section{Inclusion and exclusion criteria}

Women were included if they had singleton deliveries at 37 weeks' gestation or greater. Women were excluded from both the induction of labour group and the comparator group if they had recognised contraindications to induction of labour, including malpresentation, abdominal pregnancy, placenta praevia, or previous caesarean section. We excluded women with prelabour rupture of membranes from the induction of labour group but included them in the expectant management group if the rupture of membranes occurred after the gestation of induction of labour in the comparator group. We excluded women from both the induction of labour group and the expectant management group if they had an antepartum intrauterine death in the week of gestation in which induction of labour was performed. In Scotland, women at term are routinely seen at weekly intervals for antenatal care, which includes auscultation of the fetal heartbeat, and the standard management of antepartum stillbirth is immediate induction of labour. We therefore assumed that all babies in the expectant management group would be alive at the time that induction was initiated in the induction group. Previous studies have used a similar approach, ${ }^{3}$ supported by analysis of the database that has shown that birth weights are not indicative of prolonged maceration, which would suggest delay in delivery of stillbirths. In both groups we included women with an intrapartum death.

\section{Outcomes}

We recorded the following maternal and neonatal outcomes: extended perinatal mortality, admission of neonate to neonatal or special care unit, mode of delivery, postpartum haemorrhage, obstetric anal sphincter injury, shoulder dystocia, and uterine rupture. Extended perinatal mortality was defined as stillbirth and death in the first month of life, excluding deaths associated with congenital anomalies.

\section{Confounding factors}

The following variables, considered to be potential influences on outcomes, were included in multiple logistic regression analysis: age at delivery (years), parity (para 0 or para $\geq 1$ ), period of birth (1981-85, 1986-90, 1991-95, 1996-2000, 2001-07), deprivation fifth (defined by Carstairs 2001 deprivation fifths $1-5$ by postcode ${ }^{14}$ ), and birth weight (categorised as <2500 g, 2500-2999 g, 3000-3499 g, 3500-3999 $\mathrm{g}, 4000-4999 \mathrm{~g}, \geq 4500 \mathrm{~g}$ ). The categorisation of adjustment variables was prespecified before analysis, with the exception of birth weight. In preliminary analyses we entered birth weight 
as a continuous variable into the adjustment model, as well as categorised at $500 \mathrm{~g}$ intervals. As the results of both analyses were similar we used categorisation. Data on body mass index were only collected from 2004 onwards and as they had a significant number of missing fields were not included.

Reconfigurations in maternity services during the study period made it unfeasible to adjust for the clustering of women within obstetric unit.

\section{Statistical analysis}

To examine each confounding factor in relation to outcomes we carried out univariate analysis. Thereafter we used multivariable logistic regression modelling to examine the relation between outcomes of elective induction of labour and expectant management. Missing covariate values were not included in the analysis model. No formal tests of interaction were done. The following confounding factors were entered into the model for mode of delivery: age at delivery, parity, year of birth, birth weight, and deprivation category. The models for extended perinatal mortality, postpartum haemorrhage, obstetric anal sphincter injury, and neonatal unit admission also included mode of delivery (only women who had a vaginal delivery were included when examining anal sphincter injury). The outcomes were considered as dichotomous variables and the covariates categorised. We used the $\chi^{2}$ test for linear trend to analyse temporal trends in rates and methods of induction of labour. Number needed to treat to prevent and number needed to harm was estimated: number needed to treat to prevent/number needed to harm $=1 /$ ([induction of labour event risk]-[expectant management event risk]). The $\mathrm{P}$ values for hypothesis tests were two sided and the significance level was set at $\mathrm{P}<0.01$ to be conservative, with results presented as odds ratios with $99 \%$ confidence intervals unless otherwise stated. Analysis was done with SPSS version 17.

\section{Results}

During the study period 1605601 deliveries occurred, including 1585319 singleton pregnancies. Overall, 313770 women were excluded as they were at less than 37 weeks' gestation or had predefined exclusion criteria, leaving a cohort of 1271549 women. In total, 938364 women did not have induction of labour and 333185 women did. A medical indication for induction of labour was identified in 157049 women having induction of labour, leaving 176136 women in the elective induction of labour group.

\section{Descriptive data}

Table $1 \Downarrow$ shows the characteristics of the cohort. On univariate analysis the groups were different for each characteristic examined (age category, parity, birth weight, year of birth, and deprivation category). Women undergoing induction of labour were older, more likely to be primiparous, and less likely to be in deprivation categories 4 or 5 (highest fifths of deprivation). A higher proportion of inductions took place in the later time periods, and babies of induced mothers had higher birth weights. All characteristics were included in multivariable analysis.

\section{Secular trends in induction of labour}

Rates of elective and postdates induction of labour ( $>41$ weeks) decreased between 1981 and 1990, but rates increased from 1993 with elective induction of labour peaking at 2001 and post-dates induction of labour peaking at 2002 (figure $\Downarrow$ ). The proportion of induction of labour carried out by artificial rupture of membranes and oxytocin without preceding prostaglandins decreased from 52.02\% in 1981 to $13.61 \%$ in 2007 ( $\mathrm{P}<0.001)$, while there was a reciprocal increase in the proportion of induction of labour with prostaglandins $(\mathrm{P}<0.001$, figure $)$.

\section{Extended perinatal mortality}

Elective induction of labour was associated with a decreased odds of perinatal death at all gestations on multivariable analysis in both the primary comparator (expectant management with delivery beyond gestation of induction of labour) and secondary comparator (expectant management with delivery at or beyond gestation of induction of labour) analyses (table $2 \Downarrow$ ). Compared with expectant management, the adjusted odds ratio of perinatal death associated with elective induction of labour at 40 weeks in the primary analysis was $0.39(99 \%$ confidence interval 0.24 to $0.63,0.08 \%(37 / 44764) v 0.18 \%(627 / 350643))$ and in the secondary analysis was 0.44 (99\% confidence interval 0.27 to $0.71,0.08 \%(37 / 44764) v 0.16 \%$ (167/719 179)).

\section{Mode of delivery}

No significant differences in rates of spontaneous vertex delivery were found in association with induction of labour at 37, 38, and 39 weeks when compared with expectant management in both the primary and secondary multivariable analysis (table $3 \Downarrow$ ). In the primary analysis, at 40 and 41 weeks, induction of labour was associated with an increased odds of spontaneous vertex delivery (table 3 ; adjusted odds ratio 1.26, 99\% confidence interval 1.22 to 1.31 at 40 weeks and $1.55,1.49$ to 1.61 at 41 weeks). In the secondary analysis there was an increase in odds of spontaneous vertex delivery associated with induction of labour at 41 weeks but not at 40 weeks (table 3 ; adjusted odds ratio $1.01,99 \%$ confidence interval 0.97 to 1.05 at 40 weeks and $1.06,1.03$ to 1.09 at 41 weeks).

In the primary multivariable analysis, compared with expectant management elective induction of labour was not associated with any increase in odds of caesarean section at 37,38 , or 39 weeks' gestation, and at 40 and 41 weeks was associated with a reduction in odds of caesarean section (table 3 ). Similarly, elective induction of labour was not associated with any increase in odds of assisted vaginal delivery at 37,38 , or 39 weeks, and at 40 and 41 weeks was associated with a reduction in the odds of assisted vaginal delivery (table 3 ). In the secondary analysis a slightly different pattern was seen. Elective induction of labour was not associated with any increase in odds of caesarean delivery or assisted vaginal delivery at 37 or 38 weeks but a modest increase in caesarean section was seen in association with elective induction of labour at 39, 40, and 41 weeks (table 3). In the primary analysis, elective induction of labour at 40 weeks was associated with a decreased odds of caesarean delivery (adjusted odds ratio $0.83,99 \%$ confidence interval 0.79 to 0.88$)$ and a decreased odds of assisted vaginal delivery $(0.85$, 0.82 to 0.89 ) compared with expectant management. In the secondary analysis, elective induction of labour at 40 weeks was associated with an increased odds of caesarean section (adjusted odds ratio 1.08, 99\% confidence interval 1.03 to 1.13) but a reduced odds of assisted vaginal delivery $(0.95,0.91$ to 0.99) compared with expectant management (table 3 ).

\section{Maternal complications}

Elective induction of labour from 38 weeks onwards was associated with a decreased odds of postpartum haemorrhage compared with expectant management (table $4 \Downarrow$ ). In the primary analysis, elective induction of labour at 40 weeks was associated with a decreased odds of postpartum haemorrhage (adjusted odds ratio $0.82,99 \%$ confidence interval 0.77 to 0.86 ). In the 
secondary analysis, elective induction of labour at 40 weeks was associated with a decreased odds of postpartum haemorrhage (0.86, 0.81 to 0.91$)$.

At 39 and 40 weeks, induction of labour was also associated with a decreased odds of anal sphincter injury compared with expectant management (table $4 \Downarrow$ ). In the primary analysis, elective induction of labour at 40 weeks was associated with a decreased odds of anal sphincter injury (adjusted odds ratio $0.74,99 \%$ confidence interval 0.60 to 0.91 ) In the secondary analysis, elective induction of labour at 40 weeks was associated with a decreased odds of anal sphincter injury (adjusted odds ratio $0.77,99 \%$ confidence interval 0.63 to 0.95 ).

The incidences of uterine rupture and shoulder dystocia were low. Univariate analysis of these rare complications indicated they were more common in women with elective induction of labour than without (table $5 \Downarrow$ ). Numbers were, however, too small to meaningfully carry out multivariable analysis comparing the rates of uterine rupture and shoulder dystocia associated with induction of labour and expectant management.

\section{Neonatal admission to special care facility}

Elective induction of labour was associated with an increased odds of admission to neonatal intensive care or special care at all gestations before 41 weeks on univariate and multivariable analysis in both the primary and the secondary analysis (table $6 \Downarrow$ ). Compared with expectant management, the odds of admission to a neonatal unit associated with elective induction of labour at 40 weeks was increased in the primary analysis, with an adjusted odds ratio of 1.14 (99\% confidence interval 1.09 to 1.20$), 8.0 \%(3605 / 44778) v 7.3 \%$ (25 572/350 791)) and in the secondary analysis with an adjusted odds ratio of 1.15 (99\% confidence interval 1.10 to 1.21$), 8.0 \%$ (3605/44 778) v $7.0 \%(50064 / 719463))$.

\section{Number needed to treat and to harm}

We used the data from outcomes of elective induction of labour at 40 weeks compared with expectant management as a model to calculate the number needed to treat to prevent one case of extended perinatal mortality and number need to harm by resulting in an additional admission to a neonatal unit.

Using data from the primary analysis the number needed to treat to prevent one perinatal death was 1040 (95\% confidence interval 792 to 1513) and the number needed to harm (resulting in an admission to a neonatal unit) was 131 (95\% confidence interval 97 to 202). Thus we estimated that for every 1040 women with elective induction of labour carried out at 40 weeks, one perinatal death could be prevented, but this would be associated with seven additional admissions to the neonatal unit.

When we used data from the secondary analysis, the number needed to treat to prevent was 1257 (95\% confidence interval 928 to 1946) and the number needed to harm was 91 (95\% confidence interval 74 to 120 ). Using these data, 1257 elective inductions of labour at 40 weeks may prevent one perinatal death but could result in 13 additional admissions to the neonatal unit.

\section{Discussion}

Our data suggest that elective induction of labour at term (at 37 weeks' gestation or more) is associated with a decreased odds of perinatal death without an associated decrease in spontaneous vertex delivery. However, there was an increased risk of neonatal admission to a special care unit. As perinatal mortality increases progressively beyond 37 weeks of gestation, with antepartum stillbirth being the major factor, ${ }^{3}$ it is not surprising that induction of labour to deliver the baby decreases this risk. None the less, this is the first study that we are aware of that has quantified the benefits of induction of labour in terms of a reduction in perinatal mortality. Our findings support estimates from modelling, which have suggested similar reductions in perinatal mortality with elective delivery ${ }^{15}$ and have implications for the practice of obstetrics and the reduction in perinatal mortality in developed countries.

\section{Comparison with other studies}

The methodology and the sample size of previous studies and of our own deserve some consideration. The majority of observational studies on induction of labour have methodological problems, as has been highlighted in a review. ${ }^{16}$ In most, the comparator groups were women in spontaneous labour. The inclusion of such women is not appropriate because induction of labour is only relevant for women who are not in labour. Before the onset of labour at term women face the choice between induction of labour and expectant management (which might lead to spontaneous labour), not between induction of labour and spontaneous labour. A study using an appropriate comparator group (women undergoing expectant management) found "better" outcomes in the elective induction group. ${ }^{17}$ However, this study was small and was conducted over 25 years ago. More recently, a study found reduced caesarean section rates when women with induction of labour at term in a single centre were compared with those expectantly managed, between 1986 and $2001 .^{18}$ We recognise that the use of an expectantly managed group as a comparator is not without difficulty. In our primary analysis we used the approach endorsed by recent reviews and guidelines and compared outcomes of induction of labour at a particular gestation with the outcomes of deliveries at subsequent gestations. Other authors have argued that because some women will begin labour spontaneously during the index induction week, this week should also be included in the expectant comparison group. ${ }^{13}$ To explore potential bias in our own primary analysis, we used this strategy in a secondary analysis. A recent observational study included both methods, with 11500 women undergoing induction and 27000 women in the comparator group. This suggested induction of labour was associated with a modest increase in caesarean delivery, but the increase was only significant when the strategy employed in our secondary analysis was used. ${ }^{13}$ The effects of induction of labour on perinatal mortality were not investigated. In our study, with a population derived sample size some 30 times greater than in the previous study, we confirm that the comparator group used in the secondary method of analysis results in a higher odds ratio for caesarean section than in the method used in our primary analysis. Nevertheless, differences in the pattern of caesarean delivery associated with elective induction of labour were modest. We believe that the true association between induction of labour and caesarean section is likely to lie between the findings of our primary and secondary analysis, with little or no increase in odds of caesarean delivery in association with elective induction of labour. Both the primary and the secondary analysis showed similar patterns of reduced odds of perinatal mortality with induction of labour, supporting the robustness of this observation.

\section{Strengths and limitations of the study}

The use of an unselected population database and appropriate comparison groups are strengths of this study. This study does, however, have some weaknesses. Firstly, errors in coding are a potential source of bias, especially those relating to the 
definition of elective induction of labour. Quality assurance indicates that fields used in our study have fewer than $2 \%$ errors, except estimated gestation (error $8 \%$ ) and induction of labour (error $7 \%) .{ }^{19}$ International classification of disease codes used to determine medical indication for induction of labour are liable to greater degrees of error, but medical complications are under-recorded not over-recorded. As medical complications are associated with increased perinatal mortality and caesarean delivery (data not shown) any bias is likely to result in underestimates of the associations between elective induction of labour and these outcomes. A second limitation is that owing to lack of data we were unable to account for all potential confounding factors, including body mass index, which may be associated with higher rates of complications. Thirdly, although we did adjust for the period of birth, heterogeneity of practice over the time period may have influenced findings. Fourthly, the study may not be representative of other settings.

Another potential confounding factor is place of delivery. Potential places of delivery in Scotland include consultant led units (in which all the inductions of labour occurred), a midwifery led unit, or the woman's home. During the period of study, homebirths in Scotland comprised less than $1 \%$ of total births. Details of these births were not systematically returned to the Scottish Morbidity Record 02 and are not included in any of the study cohorts, thus they will not have introduced any bias. Less than $3 \%$ of births occurred in a stand alone midwifery unit. These units would have data returns for spontaneous labours but would not look after women undergoing induction of labour. Given the small proportion of women delivering in these units, we believe it is unlikely that there were major systematic differences between place of birth or access to midwifery or medical input between the study groups. Although we did not adjust for unit of delivery, we anticipate that approaches to care in consultant led units are similar throughout Scotland.

The characteristics of the elective induction of labour group and expectant management group were different and we adjusted for these factors in the multivariable analysis. Women undergoing elective induction of labour were more likely to be older primiparous mothers. As maternal age and primiparity are associated with stillbirth, when we adjusted for these factors it strengthened the association between induction of labour and reduced perinatal mortality. Although we intended to include only women who had a live fetus at the gestation at which induction of labour was done, it is possible that a small number were inappropriately included in the expectant management group if they had a stillbirth at or before the gestation of induction of labour, but remained undelivered until the end of that gestational week. Inclusion of these women could artificially inflate the extended perinatal mortality rate in the expectant management group. However, this bias is more likely to affect results in our secondary analysis (where expectant management included women delivering at the same gestation as induction of labour) than in our primary analysis (where expectant management was restricted to delivery beyond the gestation of induction of labour). As we found the magnitude of the reduction in perinatal mortality similar between our primary and secondary analyses it seems that the number of women in the expectant management group who had a stillbirth before the gestation of induction of labour but delayed delivery were small, and did not significantly affect the results.

\section{Conclusions and policy implications}

Our finding that elective induction of labour is not strongly associated with an increased odds of caesarean section and is associated with a reduction in maternal complications, goes against obstetric dogma but supports evidence from a recent systematic review comparing elective induction of labour with expectant management, where induction of labour was associated with about a $20 \%$ reduction in caesarean section. ${ }^{20}$ However, only two randomised controlled trials were identified as being of "good" quality. ${ }^{21}{ }^{22}$ The authors concluded that to confirm the generalisability of these findings, further well designed observational studies were required, examining the outcomes of women undergoing induction of labour compared with those expectantly managed. We believe that our study, comparing outcomes in over 176000 women undergoing induction of labour with a comparator group of 900000 women provides strong supporting evidence that elective induction of labour is not associated with a consistent increase in caesarean section rates.

Professional and consumer bodies worldwide support the need for research into methods of reducing stillbirth and neonatal death. ${ }^{23-25}$ Our data suggest that induction of labour can reduce perinatal mortality without increasing maternal complications. A caveat is that it might increase neonatal admission to special care facilities. This could represent increased respiratory morbidity associated with elective delivery at earlier gestations, given that a progressive decrease in respiratory morbidity is seen with increasing gestation beyond 37 weeks with elective delivery by caesarean section. ${ }^{26-28}$ However, further research into neonatal outcomes is required to investigate whether induction of labour has a negative impact on significant neonatal and longer term morbidity. Our data suggest that for every 1040 women with elective induction of labour at 40 weeks, one case of perinatal mortality may be prevented (95\% confidence interval 792 to 1513), but this would result in seven more admissions to a neonatal unit. Although residual confounding may remain, our findings indicate that elective induction of labour at term gestation can reduce perinatal mortality in developed countries without increasing the risk of operative delivery.

Contributors: EF, JEN, and JC conceived the study and obtained funding. SJS, EF, JC, IF, and JEN designed the study and wrote the protocol. $A D$ acquired the data. AD, SJS, JEN, and IF analysed and interpreted the data. The manuscript was drafted by SJS, with all other authors critically revising the paper. JEN is guarantor of the study. All authors had full access to all of the data (including statistical reports and tables) in the study and can take responsibility for the integrity of the data and the accuracy of the data analysis.

Funding: This study was funded by research grant CZG/2/292 from the Chief Scientist Office of the Scottish Government Health Directorate. A report was submitted to the funders following completion of the study and peer reviewed. The funders had no role in study design, data collection or analysis, or the decision to publish.

Competing interests: All authors have completed the ICMJE uniform disclosure form at www.icmje.org/coi_disclosure.pdf (available on request from the corresponding author) and declare: no support from any organisation for the submitted work; no financial relationships with any organisations that might have an interest in the submitted work in the previous three years; and no other relationships or activities that could appear to have influenced the submitted work.

Ethical approval: Record linkage was approved by the Privacy Advisory Committee of the Information and Statistics Division of the National Health Service Scotland.

Data sharing: The anonymised dataset is available from andrew.duffy@nhs.net. Consent was not obtained but the presented data are anonymised and risk of identification is low. 


\section{What is already known on this topic}

Perinatal mortality increases progressively from 37 weeks' gestation

When pregnancy is prolonged ( $>42$ weeks) induction of labour reduces perinatal mortality without increasing caesarean section rates

Evidence on the risks and benefits of induction of labour in the absence of a specific medical indication (elective induction of labour) around term is conflicting

\section{What this study adds}

Compared with expectant management, elective induction of labour between 37 and 41 weeks' gestation was associated with reduced perinatal mortality

Elective induction of labour was not associated with a reduction in spontaneous vertex delivery rates

Rates of admissions to a neonatal unit were increased in the induction of labour group

1 Mealing NM, Roberts CL, Ford JB, Simpson JM, Morris JM. Trends in induction of labour, 1998-2007: a population-based study. Aust N Z J Obstet Gynaecol 2009;49:599-605.

2 Gulmezoglu AM, Crowther CA, Middleton P. Induction of labour for improving birth outcomes for women at or beyond term. Cochrane Database Syst Rev 2006;(4):CD004945.

3 Smith GC. Life-table analysis of the risk of perinatal death at term and post term in singleton pregnancies. Am J Obstet Gynecol 2001;184:489-96.

4 Vahratian A, Zhang J, Troendle JF, Sciscione AC, Hoffman MK. Labor progression and risk of cesarean delivery in electively induced nulliparas. Obstet Gynecol 2005:105:698-704.

5 Luthy DA, Malmgren JA, Zingheim RW. Cesarean delivery after elective induction in nulliparous women: the physician effect. Am J Obstet Gynecol 2004;191:1511-5.

6 Seyb ST, Berka RJ, Socol ML, Dooley SL. Risk of cesarean delivery with elective induction of labor at term in nulliparous women. Obstet Gynecol 1999;94:600-7.

7 Glantz JC. Elective induction vs. spontaneous labor associations and outcomes. J Reprod Med 2005;50:235-40

8 Koopmans CM, Bijlenga D, Groen H, Vijgen SM, Aarnoudse JG, Bekedam DJ, et al. Induction of labour versus expectant monitoring for gestational hypertension or mild pre-eclampsia after 36 weeks' gestation (HYPITAT): a multicentre, open-label randomised controlled trial. Lancet 2009;374:979-88.

9 Smith GC, Pell JP, Dobbie R. Birth order, gestational age, and risk of delivery related perinatal death in twins: retrospective cohort study. BMJ 2002:325:1004-6.

10 Pasupathy D, Wood AM, Pell JP, Fleming M, Smith GC. Rates of and factors associated with delivery-related perinatal death among term infants in Scotland. JAMA 2009;302:660-8.

11 Smith GC, Pell JP, Dobbie R. Caesarean section and risk of unexplained stillbirth in subsequent pregnancy. Lancet 2003;362:1779-84.

12 ISD Scotland. Information Services Division. 2010. www.isdscotland.org/Health-Topics/ Maternity-and-Births/Births/.

13 Glantz JC. Term labor induction compared with expectant management. Obstet Gynecol 115:70-6.

14 Morris R, Carstairs V. Which deprivation? A comparison of selected deprivation indexes. $J$ Public Health Med 1991;13:318-26.

15 Hankins GD, Clark SM, Munn MB. Cesarean section on request at 39 weeks: impact on shoulder dystocia, fetal trauma, neonatal encephalopathy, and intrauterine fetal demise. Semin Perinatol 2006;30:276-87.

16 Caughey AB, Sundaram V, Kaimal AJ, Cheng YW, Gienger A, Little SE, et al. Maternal and neonatal outcomes of elective induction of labor. Evid Rep Technol Assess (Full Rep) 2009;176:1-257

17 Lampe LG. Elective induction of labour in the obstetrical practice. Acta Chir Hung 1986:27:143-9.
18 Caughey AB, Nicholson JM, Cheng YW, Lyell DJ, Washington AE. Induction of labor and cesarean delivery by gestational age. Am J Obstet Gynecol 2006;195:700-5.

19 Mason M. Data quality assurance: assessment of maternity data (SMR02) 2008-2009. NHS Scotland, 2010

20 Caughey AB, Sundaram V, Kaimal AJ, Gienger A, Cheng YW, McDonald KM, et al. Systematic review: elective induction of labor versus expectant management of pregnancy. Ann Intern Med 2009;151:252-63, W53-63.

21 Hannah ME, Hannah WJ, Hellmann J, Hewson S, Milner R, Willan A. Induction of labor as compared with serial antenatal monitoring in post-term pregnancy. A randomised controlled trial. The Canadian Multicenter Post-term Pregnancy Trial Group. N Engl J Med 1992;326:1587-92

22 A clinical trial of induction of labor versus expectant management in postterm pregnancy. The National Institute of Child Health and Human Development Network of Maternal-Fetal Medicine Units. Am J Obstet Gynecol 1994;170:716-23.

23 Royal College of Obstetricians and Gynaecologists. RCOG statement on the Saving Babies' Lives Report. 2009. www.rcog.org.uk/what-we-do/campaigning-and-opinions/ statement/rcog-statement-saving-babies-lives-report.

24 International Stillbirth Alliance. 2010. www.stillbirthalliance.org.

25 Scott J, Bevan C. Saving babies' lives report 2009. Stillbirth and Neonatal Death Charity, 2009.

26 Morrison JJ, Rennie JM, Milton PJ. Neonatal respiratory morbidity and mode of delivery at term: influence of timing of elective caesarean section. Br J Obstet Gynaecol 1995;102:101-6.

27 Hansen AK, Wisborg K, Uldbjerg N, Henriksen TB. Risk of respiratory morbidity in term infants delivered by elective caesarean section: cohort study. BMJ 2008;336:85-7.

28 Zanardo V, Simbi AK, Franzoi M, Solda G, Salvadori A, Trevisanuto D. Neonatal respiratory morbidity risk and mode of delivery at term: influence of timing of elective caesarean delivery. Acta Paediatr 2004:93:643-7.

\section{Accepted: 22 March 2012}

\section{Cite this as: BMJ 2012;344:e2838}

This is an open-access article distributed under the terms of the Creative Commons Attribution Non-commercial License, which permits use, distribution, and reproduction in any medium, provided the original work is properly cited, the use is non commercial and is otherwise in compliance with the license. See: http://creativecommons.org/licenses/by$\mathrm{nc} / 2.0 /$ and http://creativecommons.org/licenses/by-nc/2.0/legalcode. 


\section{Tables}

Table 1| Personal characteristics of women according to induction of labour

\begin{tabular}{|c|c|c|c|c|}
\hline \multirow[b]{2}{*}{ Characteristics } & \multirow[b]{2}{*}{ Total } & \multicolumn{2}{|c|}{ No $(\%)$ in group } & \multirow[b]{2}{*}{$P$ value } \\
\hline & & No induction of labour & Elective induction of labour & \\
\hline \multicolumn{5}{|l|}{ Age group: } \\
\hline$<20$ & 103475 & $88288(9.4)$ & $15187(8.6)$ & $<0.001$ \\
\hline $20-24$ & 278376 & $236250(25.2)$ & $42126(23.9)$ & $<0.001$ \\
\hline $25-29$ & 361401 & $305588(32.6)$ & $55813(31.7)$ & $<0.001$ \\
\hline $30-34$ & 261186 & $218263(23.3)$ & $42923(24.4)$ & $<0.001$ \\
\hline $35-39$ & 95580 & $78507(8.4)$ & $17073(9.7)$ & $<0.001$ \\
\hline$\geq 40$ & 14482 & $11468(1.2)$ & $3014(1.7)$ & $<0.001$ \\
\hline \multicolumn{5}{|l|}{ Parity: } \\
\hline 0 & 514904 & $431571(46.0)$ & $83333(47.3)$ & $<0.001$ \\
\hline 1 & 599596 & $506793(54.0)$ & $92803(52.7)$ & $<0.001$ \\
\hline \multicolumn{5}{|c|}{ Birth weight group $(\mathrm{g})$ : } \\
\hline$<2500$ & 22968 & $19613(2.1)$ & $3355(1.9)$ & $<0.001$ \\
\hline $2500-2999$ & 162242 & $143404(15.3)$ & $18838(10.7)$ & $<0.001$ \\
\hline $3000-3499$ & 431015 & $371816(39.6)$ & $59199(33.6)$ & $<0.001$ \\
\hline 3500-3999 & 363018 & $298896(31.9)$ & $64122(36.4)$ & $<0.001$ \\
\hline $4000-4499$ & 116129 & $90399(9.6)$ & $25730(14.6)$ & $<0.001$ \\
\hline$\geq 4500$ & 18593 & $13778(1.5)$ & $4815(2.7)$ & $<0.001$ \\
\hline Missing & 535 & $458(0.05)$ & $77(0.04)$ & - \\
\hline \multicolumn{5}{|l|}{ Year of birth: } \\
\hline 1981-85 & 228059 & $192557(20.5)$ & $35502(20.2)$ & $<0.001$ \\
\hline $1986-90$ & 224171 & $199880(21.3)$ & 24291 (13.8) & $<0.001$ \\
\hline 1991-95 & 309975 & $186406(19.9)$ & $23569(13.4)$ & $<0.001$ \\
\hline $1996-2000$ & 196634 & $159465(17.0)$ & $37169(21.2)$ & $<0.001$ \\
\hline 2001-07 & 255661 & $200056(21.3)$ & $55605(31.6)$ & $<0.001$ \\
\hline \multicolumn{5}{|c|}{ Carstairs 2001 deprivation fifths: } \\
\hline 1 (least deprived) & 187148 & $157732(16.8)$ & $29416(16.7)$ & $<0.001$ \\
\hline 2 & 202036 & $169427(18.1)$ & $32612(18.5)$ & $<0.001$ \\
\hline 3 & 208034 & $174876(18.6)$ & 33148 (18.8) & $<0.001$ \\
\hline 4 & 229923 & $193433(20.6)$ & $36490(20.7)$ & $<0.001$ \\
\hline 5 (most deprived) & 260416 & $222152(23.7)$ & $38264(21.7)$ & $<0.001$ \\
\hline Missing & 26950 & $20744(2.2)$ & $6206(3.5)$ & - \\
\hline
\end{tabular}


Table 2| Extended perinatal mortality after elective induction of labour (IOL) compared with expectant management

\begin{tabular}{|c|c|c|c|c|c|c|}
\hline \multirow{2}{*}{$\begin{array}{l}\text { Gestation } \\
\text { week of } \\
\text { IOL }\end{array}$} & \multicolumn{2}{|c|}{ No with outcome/Total No in group (\%) } & \multicolumn{2}{|c|}{ Univariate analysis, IOL $v$ expectant } & \multicolumn{2}{|c|}{ Multivariable analysis, IOL $v$ expectant } \\
\hline & Expectant management & Elective IOL & Odds ratio $(99 \% \mathrm{Cl})$ & $P$ value & $\begin{array}{l}\text { Adjusted odds ratio* }(99 \% \\
\text { Cl) }\end{array}$ & $P$ value \\
\hline \multicolumn{7}{|c|}{ Primary analysis: comparator delivery beyond gestation of IOL } \\
\hline 37 & $2829 / 1213639(0.23)$ & $4 / 4429(0.90)$ & $0.39(0.11$ to 1.40$)$ & 0.0578 & $0.15(0.03$ to 0.68$)$ & 0.001 \\
\hline 38 & $2190 / 1073170(0.20)$ & $9 / 11384(0.08)$ & $0.39(0.16$ to 0.92$)$ & 0.0045 & $0.23(0.09$ to 0.58$)$ & $<0.001$ \\
\hline 39 & $1521 / 810720(0.19)$ & 9/16 $344(0.06)$ & $0.29(0.12$ to 0.69$)$ & 0.0002 & $0.26(0.11$ to 0.62$)$ & $<0.001$ \\
\hline 40 & $627 / 350643(0.18)$ & $37 / 44764(0.08)$ & $0.46(0.30$ to 0.71$)$ & $<0.001$ & $0.39(0.24$ to 0.63$)$ & $<0.001$ \\
\hline 41 & $127 / 58028(0.22)$ & $50 / 76028(0.07)$ & $0.30(0.20$ to 0.46$)$ & $<0.001$ & $0.31(0.19$ to 0.49$)$ & $<0.001$ \\
\hline \multicolumn{7}{|c|}{ Secondary analysis: comparator delivery at or beyond gestation of IOL } \\
\hline 37 & $3076 / 1257029(0.24)$ & $4 / 4429(0.90)$ & $0.37(0.10$ to 1.34$)$ & 0.046 & $0.15(0.03$ to 0.68$)$ & $<0.001$ \\
\hline 38 & $2514 / 1180899(0.21)$ & $9 / 11384(0.08)$ & $0.37(0.16$ to 0.88$)$ & $<0.001$ & $0.24(0.10$ to 0.60$)$ & $<0.001$ \\
\hline 39 & $1896 / 1028735(0.18)$ & 9/16 $344(0.06)$ & $0.30(0.13$ to 0.71$)$ & $<0.001$ & $0.28(0.12$ to 0.67$)$ & $<0.001$ \\
\hline 40 & $1167 / 719179(0.16)$ & $37 / 44764(0.08)$ & 0.51 (0.33 to 0.78$)$ & $<0.001$ & 0.44 (0.27 to 0.71$)$ & $<0.001$ \\
\hline 41 & $373 / 233065(0.16)$ & $50 / 76028(0.07)$ & $0.41(0.28$ to 0.61$)$ & $<0.001$ & $0.42(0.28$ to 0.63$)$ & $<0.001$ \\
\hline
\end{tabular}

${ }^{*}$ Adjusted for age, parity, period of delivery, deprivation category, and birth weight. 


\begin{tabular}{|c|c|c|c|c|c|c|}
\hline \multirow{2}{*}{$\begin{array}{l}\text { Mode of } \\
\text { delivery: } \\
\text { gestation week } \\
\text { of IOL }\end{array}$} & \multicolumn{2}{|c|}{ No with outcome/Total No in group (\%) } & \multicolumn{2}{|c|}{ Univariate analysis, IOL $v$ expectant } & \multicolumn{2}{|c|}{ Multivariable analysis, IOL $v$ expectant } \\
\hline & Expectant management & Elective IOL & Odds ratio $(99 \% \mathrm{Cl})$ & $P$ value & $\begin{array}{l}\text { Adjusted odds } \\
\text { ratio* }(99 \% \mathrm{Cl})\end{array}$ & \\
\hline \multicolumn{7}{|c|}{ Primary analysis: comparator delivery beyond gestation of IOL } \\
\hline \multicolumn{7}{|l|}{$\begin{array}{l}\text { Spontaneous } \\
\text { vertex delivery: }\end{array}$} \\
\hline 37 & 958 840/1 $214245(79.0)$ & $3517 / 4432(79.4)$ & $1.02(0.93$ to 1.13$)$ & 0.526 & $1.06(0.95$ to 1.18$)$ & 0.173 \\
\hline 38 & 846 726/1 073649 (78.9) & $9221 / 11390(81.0)$ & $1.14(1.07$ to 1.21$)$ & $<0.001$ & $1.05(0.98$ to 1.13$)$ & 0.052 \\
\hline 39 & $632533 / 811057(78.0)$ & $12891 / 16347(78.9)$ & $1.05(1.00$ to 1.11$)$ & 0.008 & 0.99 (0.94 to 1.05$)$ & 0.716 \\
\hline 40 & $258655 / 350791(73.7)$ & $35775 / 44778(79.9)$ & $1.42(1.37$ to 1.46$)$ & $<0.001$ & $1.26(1.22$ to 1.31$)$ & $<0.001$ \\
\hline 41 & 40 024/58 052 (68.9) & 57 849/76 054 (76.1) & 1.43 (1.39 to 1.48$)$ & $<0.001$ & 1.55 (1.49 to 1.61$)$ & $<0.001$ \\
\hline \multicolumn{7}{|l|}{$\begin{array}{l}\text { Caesarean } \\
\text { delivery: }\end{array}$} \\
\hline 37 & $100854 / 1214245(8.3)$ & 439/4432 (9.9) & 1.21 (1.07 to 1.38$)$ & $<0.001$ & $1.02(0.89$ to 1.17$)$ & 0.662 \\
\hline 38 & 86 948/1 073649 (8.0) & $998 / 11390(8.8)$ & 1.09 (1.00 to 1.19$)$ & 0.010 & $1.03(0.94$ to 1.13$)$ & 0.352 \\
\hline 39 & 67 828/811 057 (8.4) & $1524 / 16347$ (9.3) & $1.13(1.05$ to 1.21$)$ & $<0.001$ & 1.08 (1.00 to 1.16$)$ & 0.007 \\
\hline 40 & 37 892/350 791 (10.8) & $3740 / 44778(8.4)$ & 0.75 (0.72 to 0.79$)$ & $<0.001$ & 0.83 (0.79 to 0.88$)$ & $<0.001$ \\
\hline 41 & $8161 / 58052(14.1)$ & $8154 / 76054$ (10.7) & 0.73 (0.70 to 0.77$)$ & $<0.001$ & 0.66 (0.63 to 0.69$)$ & $<0.001$ \\
\hline \multicolumn{7}{|l|}{$\begin{array}{l}\text { Assisted vaginal } \\
\text { delivery: }\end{array}$} \\
\hline 37 & $146580 / 1214245$ (12.1) & $430 / 4432(9.7)$ & $0.78(0.69$ to 0.89$)$ & $<0.001$ & $0.93(0.81$ to 1.06$)$ & 0.157 \\
\hline 38 & $132683 / 1073649$ (12.4) & $1095 / 11390(9.6)$ & 0.75 (0.69 to 0.82$)$ & $<0.001$ & 0.95 (0.87 to 1.04$)$ & 0.168 \\
\hline 39 & $104871 / 811057$ (12.9) & 1779/16 347 (10.9) & $0.82(0.77$ to 0.88$)$ & $<0.001$ & 0.98 (0.91 to 1.05$)$ & 0.418 \\
\hline 40 & 51 044/350 791 (14.6) & $4959 / 44778(11.1)$ & $0.73(0.70$ to 0.76$)$ & $<0.001$ & 0.85 (0.82 to 0.89$)$ & $<0.001$ \\
\hline 41 & $9489 / 58052(16.3)$ & $9124 / 76054(12.0)$ & $0.70(0.67$ to 0.73$)$ & $<0.001$ & $0.78(0.74$ to 0.81$)$ & $<0.001$ \\
\hline \multicolumn{7}{|c|}{ Secondary analysis: comparator delivery at or beyond gestation of IOL } \\
\hline \multicolumn{7}{|l|}{$\begin{array}{l}\text { Spontaneous } \\
\text { vertex delivery: }\end{array}$} \\
\hline 37 & $994061 / 1257689(79.0)$ & $3517 / 4432(79.4)$ & $1.02(0.93$ to 1.12$)$ & 0.606 & $1.05(0.95$ to 1.17$)$ & 0.200 \\
\hline 38 & 934 480/1 $181455(79.1)$ & $9221 / 11390(81.0)$ & $1.12(1.06$ to 1.20$)$ & $<0.001$ & $1.06(0.99$ to 1.13$)$ & 0.040 \\
\hline 39 & 814 172/1 $029168(79.1)$ & $12891 / 16347(78.9)$ & $0.98(0.94$ to 1.04$)$ & 0.433 & $0.94(0.89$ to 1.00$)$ & 0.008 \\
\hline 40 & $565447 / 719463(78.6)$ & 35 775/44 778 (79.9) & $1.08(1.05$ to 1.12$)$ & $<0.001$ & $1.01(0.97$ to 1.05$)$ & 0.518 \\
\hline 41 & $176513 / 233155$ (75.7) & 57 849/76 054 (76.1) & 1.02 (0.99 to 1.05$)$ & 0.046 & 1.06 (1.03 to 1.09$)$ & $<0.001$ \\
\hline \multicolumn{7}{|l|}{$\begin{array}{l}\text { Caesarean } \\
\text { delivery: }\end{array}$} \\
\hline 37 & 105 282/1 $257689(8.4)$ & 439/4432 (9.9) & 1.20 (1.06 to 1.37$)$ & $<0.001$ & $1.01(0.88$ to 1.16$)$ & 0.805 \\
\hline 38 & 97 140/1 181455 (8.2) & $998 / 11390(8.8)$ & 1.07 (0.98 to 1.17$)$ & 0.037 & 0.99 (0.91 to 1.08$)$ & 0.769 \\
\hline 39 & 82 043/1 029168 (8.0) & 1524/16 347 (9.3) & 1.19 (1.11 to 1.27$)$ & $<0.001$ & $1.10(1.02$ to 1.19$)$ & $<0.001$ \\
\hline 40 & 90 781/719 463 (8.1) & $3740 / 44778(8.4)$ & 1.04 (0.99 to 1.09$)$ & 0.024 & 1.08 (1.03 to 1.13$)$ & $<0.001$ \\
\hline 41 & 22 285/233 155 (9.6) & $8154 / 76054(10.7)$ & 1.14 (1.10 to 1.18$)$ & $<0.001$ & $1.06(1.02$ to 1.11$)$ & $<0.001$ \\
\hline \multicolumn{7}{|l|}{$\begin{array}{l}\text { Assisted vaginal } \\
\text { delivery: }\end{array}$} \\
\hline 37 & 150 171/1 257689 (11.9) & $430 / 4432(9.7)$ & $0.79(0.70$ to 0.90$)$ & $<0.001$ & 0.94 (0.82 to 1.08$)$ & 0.243 \\
\hline 38 & 142 066/1 181455 (12.0) & $1095 / 11390(9.6)$ & $0.78(0.72$ to 0.84$)$ & $<0.001$ & 0.98 (0.90 to 1.07$)$ & 0.600 \\
\hline 39 & $125977 / 1029168$ (12.2) & 1779/16 347 (10.9) & $0.88(0.82$ to 0.93$)$ & $<0.001$ & $1.03(0.96$ to 1.10$)$ & 0.274 \\
\hline 40 & 57 943/719 463 (12.6) & 4959/44 778 (11.1) & $0.86(0.83$ to 0.90$)$ & $<0.001$ & 0.95 (0.91 to 0.99$)$ & 0.003 \\
\hline 41 & 32 502/233 155 (13.9) & $9124 / 76054(12.0)$ & $0.84(0.81$ to 0.87$)$ & $<0.001$ & $0.88(0.85$ to 0.91$)$ & $<0.001$ \\
\hline
\end{tabular}




\begin{tabular}{|c|c|c|c|c|c|c|}
\hline \multirow[b]{2}{*}{$\begin{array}{l}\text { Complication:gestation } \\
\text { week of IOL }\end{array}$} & \multicolumn{2}{|c|}{ No with outcome/Total No in group (\%) } & \multicolumn{2}{|c|}{ Univariate analysis, IOL $v$ expectant } & \multicolumn{2}{|c|}{ Multivariable analysis, IOL $v$ expectant } \\
\hline & Expectant management & Elective IOL & Odds ratio $(99 \% \mathrm{Cl})$ & $P$ value & $\begin{array}{l}\text { Adjusted odds ratio* } \\
(99 \% \mathrm{Cl})\end{array}$ & $P$ value \\
\hline \multicolumn{7}{|c|}{ Primary analysis: comparator delivery beyond gestation of IOL } \\
\hline \multicolumn{7}{|l|}{ Postpartum haemorrhage: } \\
\hline 37 & 85 526/1 $214245(7.0)$ & $273 / 4432(6.2)$ & $0.87(0.74$ to 1.02$)$ & 0.002 & $0.87(0.73$ to 1.03$)$ & 0.034 \\
\hline 38 & $76701 / 1073649(7.1)$ & $693 / 11390(6.1)$ & $0.84(0.76$ to 0.93$)$ & $<0.001$ & $0.85(0.76$ to 0.95$)$ & $<0.001$ \\
\hline 39 & 60 258/811 $057(7.4)$ & $1146 / 16347(7.0)$ & 0.94 (0.87 to 1.02$)$ & $<0.001$ & 0.90 (0.83 to 0.98$)$ & 0.002 \\
\hline 40 & $31313 / 350791(8.9)$ & 2845/44 $778(6.4)$ & 0.69 (0.66 to 0.73$)$ & $<0.001$ & $0.82(0.77$ to 0.86$)$ & $<0.001$ \\
\hline 41 & $5603 / 58052(9.7)$ & $6023 / 76054(7.9)$ & $0.81(0.77$ to 0.85$)$ & $<0.001$ & 0.75 (0.71 to 0.79$)$ & $<0.001$ \\
\hline \multicolumn{7}{|l|}{ Anal sphincter injury: } \\
\hline 37 & $5911 / 1113391(0.53)$ & $12 / 3993(0.30)$ & $0.56(0.27$ to 1.19$)$ & 0.048 & 0.69 (0.33 to 1.47$)$ & 0.206 \\
\hline 38 & $5449 / 986701(0.55)$ & $45 / 10392(0.43)$ & $0.78(0.53$ to 1.15$)$ & 0.103 & $0.87(0.58$ to 1.31$)$ & 0.390 \\
\hline 39 & $4349 / 743229(0.59)$ & $55 / 14823(0.37)$ & $0.63(0.45$ to 0.90$)$ & $<0.001$ & $0.62(0.43$ to 0.89$)$ & $<0.001$ \\
\hline 40 & $2216 / 312899(0.71)$ & $188 / 41038(0.46)$ & 0.65 (0.53 to 0.79$)$ & $<0.001$ & $0.74(0.60$ to 0.91$)$ & $<0.001$ \\
\hline 41 & $354 / 49891(0.71)$ & $512 / 67900(0.75)$ & $1.06(0.89$ to 1.27$)$ & 0.377 & $0.87(0.71$ to 1.05$)$ & 0.006 \\
\hline \multicolumn{7}{|c|}{ Secondary analysis: comparator delivery at or beyond gestation of IOL } \\
\hline \multicolumn{7}{|l|}{ Postpartum haemorrhage: } \\
\hline 37 & 88 046/1 $257689(8.4)$ & $273 / 4432(6.2)$ & $0.87(0.72$ to 1.02$)$ & 0.029 & $0.86(0.73$ to 1.02$)$ & 0.027 \\
\hline 38 & $82835 / 1181455(8.2)$ & $693 / 11390(6.1)$ & $0.86(0.78$ to 0.95$)$ & $<0.001$ & 0.85 (0.77 to 0.95$)$ & $<0.001$ \\
\hline 39 & $72882 / 1029168(8.0)$ & $1146 / 16347(7.0)$ & $0.99(0.91$ to 1.07$)$ & 0.725 & $0.91(0.84$ to 0.99$)$ & 0.005 \\
\hline 40 & $52886 / 719463(8.1)$ & $2845 / 44778(6.4)$ & $0.86(0.81$ to 0.90$)$ & $<0.001$ & $0.86(0.81$ to 0.91$)$ & $<0.001$ \\
\hline 41 & 19 108/233 155 (9.6) & 6023/76 054 (7.9) & $0.96(0.93$ to 1.00$)$ & 0.016 & $0.82(0.78$ to 0.85$)$ & $<0.001$ \\
\hline \multicolumn{7}{|l|}{ Anal sphincter injury: } \\
\hline 37 & $6036 / 1152407$ (0.52) & $12 / 3993(0.30)$ & $0.57(0.27$ to 1.21$)$ & 0.054 & $0.70(0.33$ to 1.49$)$ & 0.226 \\
\hline 38 & $5791 / 1084315(0.53)$ & $45 / 10392(0.43)$ & $0.81(0.55$ to 1.19$)$ & 0.160 & 0.89 (0.59 to 1.32$)$ & 0.436 \\
\hline 39 & $5287 / 947125(0.56)$ & $55 / 14823(0.37)$ & $0.66(0.47$ to 0.94$)$ & 0.003 & $0.63(0.44$ to 0.91$)$ & 0.001 \\
\hline 40 & $3950 / 661520(0.60)$ & $188 / 41038(0.46)$ & 0.77 (0.63 to 0.93$)$ & $<0.001$ & 0.77 (0.63 to 0.95$)$ & 0.001 \\
\hline 41 & $1410 / 210870(0.67)$ & $512 / 67900(0.75)$ & $1.13(0.99$ to 1.29$)$ & 0.019 & $0.93(0.81$ to 1.07$)$ & 0.187 \\
\hline
\end{tabular}

*Adjusted for age, parity, period of delivery, mode of delivery, deprivation category, and birth weight. 
Table 5| Rare maternal complications in women with and without elective induction of labour (IOL) at 37 weeks' gestation or more. Values are numbers of women experiencing event/total number (percentage) unless stated otherwise

No with outcome/Total No in group (\%)

Complication Elective IOL No IOL Odds ratio $(99 \% \mathrm{Cl}) \quad \mathrm{P}$ value

Uterine rupture $\quad 50 / 333185(0.015) \quad 83 / 938364(0.009) \quad 1.70(1.07$ to 2.69$) \quad 0.039$

Shoulder dystocia* $1311 / 318330(0.41) \quad 2741 / 852365(0.32) \quad 1.28(1.17$ to 1.39$) \quad<0.001$

${ }^{*}$ In women with vaginal delivery. 
Table 6| Neonatal admission to neonatal unit or special care baby unit after elective induction of labour (IOL) compared with expectant management

$\begin{array}{ll}\text { Gestation } & \text { No with outcome/Total No in group (\%) Univariate analysis, IOL } v \text { expectant } \\ \text { week of } & \end{array}$

week of

Expectant management

Elective IOL Odds ratio $(99 \% \mathrm{Cl})$

P value

Multivariable analysis, IOL $v$ expectant

Primary analysis: comparator delivery beyond gestation of IOL

\begin{tabular}{|c|c|c|c|c|c|c|}
\hline 37 & 95 309/1 214245 (7.8) & 782/4432 (17.6) & 2.52 (2.27 to 2.79 ) & $<0.001$ & 2.01 (1.80 to 2.25 ) & $<0.001$ \\
\hline 38 & 79 204/1 $073649(7.4)$ & $1283 / 11390(11.3)$ & 1.59 (1.48 to 1.72$)$ & $<0.001$ & 1.53 (1.41 to 1.67$)$ & $<0.001$ \\
\hline 39 & 59 285/811 057 (7.3) & 1310/16 347 (9.3) & 1.10 (1.02 to 1.19$)$ & 0.001 & 1.17 (1.07 to 1.26$)$ & $<0.001$ \\
\hline 40 & 25 572/350 791 (7.3) & $3605 / 44778(8.0)$ & 1.11 (1.06 to 1.17$)$ & $<0.001$ & 1.14 (1.09 to 1.20$)$ & $<0.001$ \\
\hline 41 & $4859 / 58052(8.4)$ & $5051 / 76054(6.6)$ & 0.78 (0.74 to 0.82$)$ & $<0.001$ & 0.99 (0.93 to 1.05$)$ & 0.618 \\
\hline \multicolumn{7}{|c|}{ Secondary analysis: comparator delivery at or beyond gestation of IOL } \\
\hline 37 & 102 606/1 257689 (8.2) & 782/4432 (17.6) & 2.41 (2.18 to 2.67 ) & $<0.001$ & 1.92 (1.71 to 2.15$)$ & $<0.001$ \\
\hline 38 & 89 987/1 181455 (7.2) & $1283 / 11390(11.3)$ & 1.54 (1.43 to 1.66$)$ & $<0.001$ & 1.49 (1.37 to 1.62$)$ & $<0.001$ \\
\hline 39 & 74 099/1 029168 (7.2) & 1310/16 347 (9.3) & $1.12(1.04$ to 1.21$)$ & $<0.001$ & 1.18 (1.09 to 1.28$)$ & $<0.001$ \\
\hline 40 & 50 064/719 $463(7.0)$ & $3605 / 44778(8.0)$ & 1.17 (1.12 to 1.23$)$ & $<0.001$ & $1.15(1.10$ to 1.21$)$ & $<0.001$ \\
\hline 41 & 16 191/233 155 (6.9) & $5051 / 76054$ (6.6) & 0.95 (0.91 to 1.00$)$ & 0.004 & 1.04 (0.99 to 1.09$)$ & 0.024 \\
\hline
\end{tabular}

${ }^{*}$ Adjusted for age, parity, period of delivery, mode of delivery, deprivation category, and birth weight. 


\section{Figure}

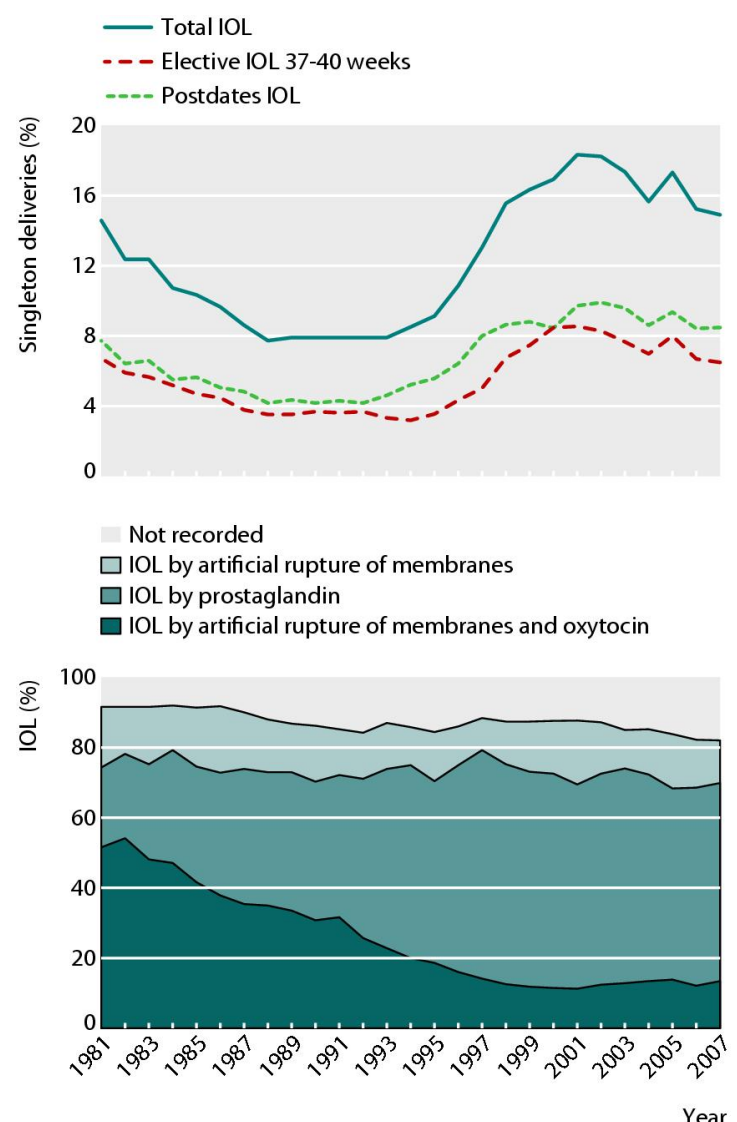

(Top) Percentage of induced singleton deliveries (total induction of labour, IOL) in Scotland 1981-2007, with proportion of elective inductions (no recognised medical indication) and postdates inductions (no recognised medical indication but $\geq 41$ weeks' gestation). (Bottom) Proportion of induced labour carried out by artificial rupture of membranes (with or without oxytocin) or by prostaglandins in Scotland 1981-2007 